\title{
Cable Car Speed Control Using Programmable Logic Control Based on Fuzzy Logic
}

\author{
Santi Triwijaya, Arief Darmawan, Andri Pradipta, Dara Aulia Feriando \\ Department of Railway Electrical Technology Politeknik Perkeretaapian Indonesia, Madiun \\ J1. Tirta Raya, Nambangan Lor, Manguharjo, Madiun, Indonesia
}

\begin{tabular}{ll}
\hline \multicolumn{1}{c}{ Article Info } & Abstract \\
\hline $\begin{array}{l}\text { Article History: } \\
\text { Received Sept } 15,2020\end{array}$ & $\begin{array}{l}\text { Transportation is very important to support economic improvement. Especially for areas with } \\
\text { difficult access. An example is farming in mountainous areas that have difficult to reach. For this } \\
\text { reason, transportation is needed that can help accommodate the mobilization of agricultural } \\
\text { commodities. The cable car can be a solution to this problem. A cable car is a hanging streetcar that } \\
\text { operates overhead and moved by gripping to the rotating cable along the track. Cable car carrier } \\
\text { Accepted Oct } 21,2020\end{array}$ \\
$\begin{array}{l}\text { controlled by DC motor. Aim to increase the safety and reliability operation of cable car, it is } \\
\text { necessary to control the speed of the cable car. Simulation of a cable car speed control with } \\
\text { Programmable Logic Control (PLC) using Fuzzy Logic method has been made. The parameters } \\
\text { Cable Car }\end{array}$ & $\begin{array}{l}\text { considered in this study are wind speed, maximum load weight, and distance (meters). From the } \\
\text { results obtained, the PLC has worked well in regulating the speed of cable car. if any parameter } \\
\text { exceeds the PLC limit, it can turn off the cable car. }\end{array}$ \\
PLC &
\end{tabular}

Control system

Safety and Reliability

\author{
Corresponding Author: \\ santi@ppi.ac.id, \\ Department of Railway Electrical Technology \\ Politeknik Perkeretaapian Indonesia
}

This work is an open-access article and licensed under a Creative Commons Attribution-ShareAlike 4.0 International License (CC BY-SA 4.0).

\section{INTRODUCTION}

In the sundry types of motors available, DC motors have advantages compared to other types of motors. One of the advantages of a DC motor is easy to control the speed [1]. So, some of the hanging trains used motor DC in operation. The cable car operates by hanging and walking based on the drive of the cable above it. The cable car transportation can be an innovation in transport interconnection in areas with arduous access or as a solution for areas with dense traffic. The track area of cable car is geographically adapted and generally only turns at small angles at intermediate stations. The biggest challenge in the operation of the cable car is in maintaining stability. Control the speed profile of the cable car cable needed dynamic and precise calculations [2]. However, it's not easy for the application, because the connection system for the transport cable which is driven is time dependent, the support cable, the suspension of the carrier cable on the support cable, the counter weight and one or two vehicles, as well as several damping devices must be taken into account. Wind conditions can cause oscillations in cables and cable cars [3]. So that it affects the stability of the movement of the vehicle.
The speed of movement of the cable as a cable car carrier is determined by the rotation of the motor in the power house. Today, most speed control, rotational or linear, using digital or microprocessor based controllers employ some combination of PID control schemes [4]. PID-based controllers are usually very reliable, however, they often have some limitations that can drastically reduce their performance namely (1) The PID speed controller is implemented using a dedicated controller, which can increase the cost of the overall control system (2) PID controllers are often limited in cases where highly nonlinear and does not respond with the accuracy required to obtain acceptable control and (3) PID controllers require system designers to develop mathematical control models that are extensive and not always easy to achieve.

Thus, fuzzy can be used as an alternative to speed control from within the PLC without using any control schemes other than PID [5], [6], [7]. In the decision making process using fuzzy logic, there is a membership function that is used to process input data. PLC as a digital electronic instrument that uses programmable memory as internal storage of a set of instructions by implementing certain functions. 
In this research, the velocity profile of the cable car carrier is controlled by fuzzy logic method, then implemented in the PLC So the oscillations that may occur will be minimized and increasing the safety and reliability operation of cable cars. In this research, the determination of the parameter value was carried out by approaching the actual conditions.

\section{MATERIALS AND METHODS}

\section{A. Logika Fuzzy}

Fuzzy logic is a logic that can be used as a process control in decision making and is based on rules (or rule-based) [Srivastava 2011]. In Rule-based, there is a set of fuzzy rules in the form of IF - THEN to determine the output of a given controller from a set of inputs. So you don't have to develop complex mathematical models to design controllers that can function properly and effectively.

This can save time especially for systems with nonlinear models and difficult differential equations. In fuzzy based control, the term linguistics are used to create fuzzy subsets, fuzzy rule bases, and fuzzy outputs. Fuzzy rule base is developed from one or more knowledge about the device or process to be controlled. The fuzzy control scheme consists of several different stages, including the fuzzification process, rule-base, and defuzzification process, as illustrated in Figure 1.

Membership function (membership function) is a curve that shows the mapping of data input points into their membership values. Rule Base is a set of rules based on membership functions. Defuzzification is changing the result of the rule base matrix to be translated into the PLC input [10-17]. In the Fuzzy system, there are several membership functions, in this study using the triangular membership function. Equation 1 is the formulation of the triangular membership function in fuzzy logic.

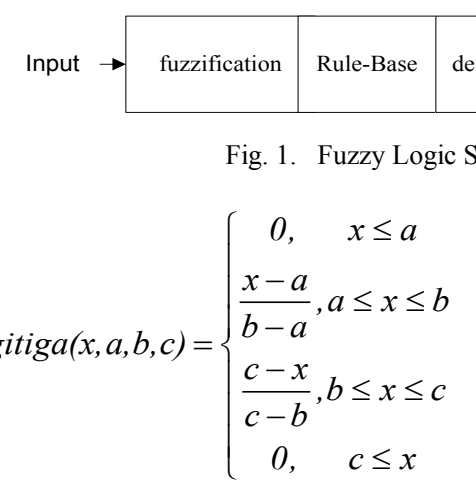

\section{B. Application of Fuzzy Logic to PLC}

Fuzzy logic is intended to make rules for the speed of movement of the cable car which controls the input on the PLC in order to control the output. Controlling the speed of the DC motor in driving the cable car is influenced by wind speed and load weight. In accordance with Law No. 23 of 2007, a cable car is a train that moves by hanging from a steel rope. For that we need a motor speed regulation based on the influence of wind speed. Meanwhile, to maintain the lifetime, reliability and safety of the train, it is necessary to know the maximum weight allowed in the cable car operation. The maximum load of the cable car can be determined based on the specified design. In this study, the maximum load weight of the cable car is assumed. Where the allowable load weight must be less than equal to the maximum allowable load weight. If the weight of the cargo is more than the maximum allowable weight, the cable car is not allowed to run. The working scheme of the cable car speed control system with fuzzy logic - PLC is represented in Figure 2.

In the wind speed variation, three fuzzy sets are defined, namely slow, normal, and fast. To present the wind speed variables, the curve shape of the left shoulder is used for the slow fuzzy set, the triangle curve for the normal fuzzy set and the right shoulder curve in the fast fuzzy set. To the wind speed membership function is presented in Figure 3, the horizontal axis is the input value in the form of wind speed in $\mathrm{km} /$ hour and the vertical axis is the membership level of the input value. In this study, the value of wind speed was carried out based on the average daily wind speed in Sarangan, East Java with a maximum speed of $16 \mathrm{~km} /$ hour

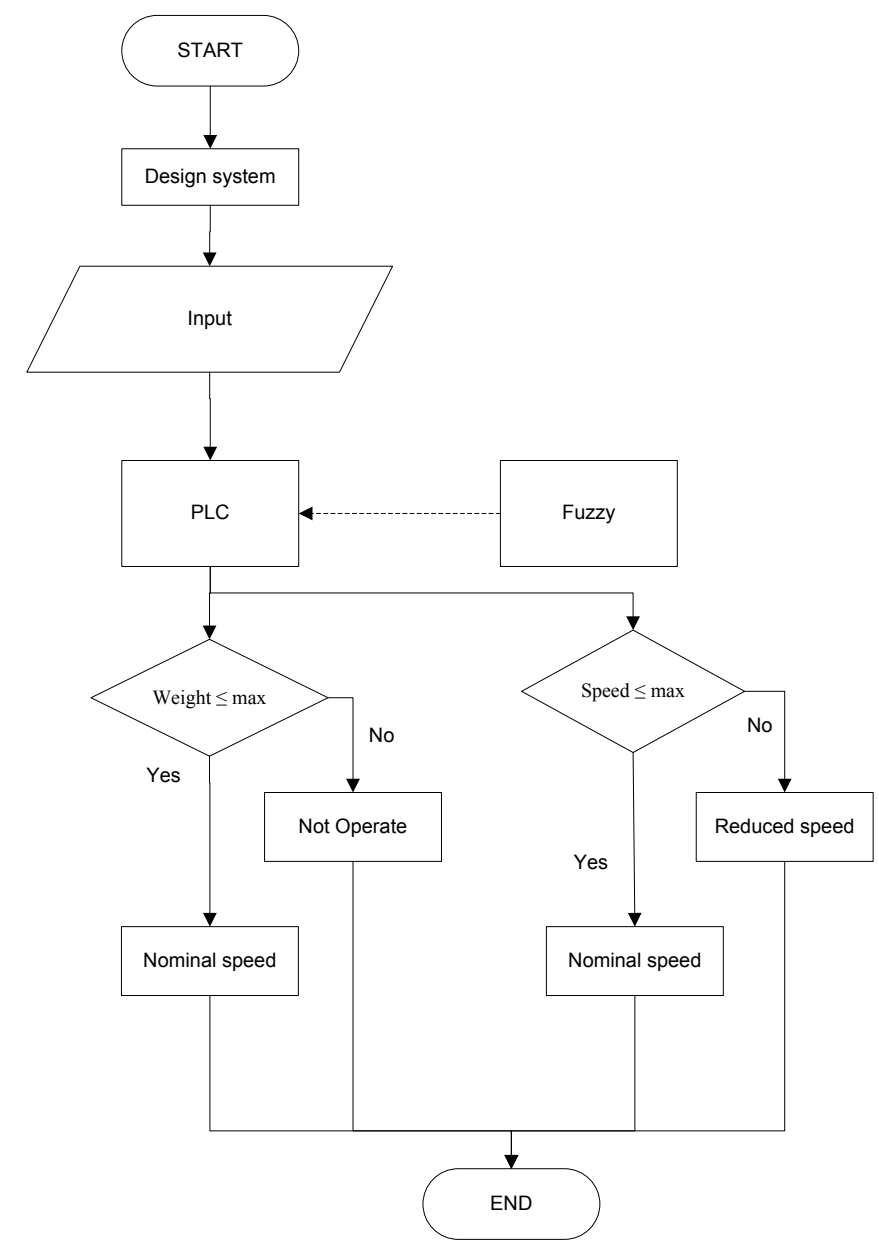

Fig. 2. The block diagram of cable car system 
. The weight membership function is presented in Figure 4 with the membership function used is a triangle function with three membership limits including slow, normal, and fast. In this research, it is simulated that the maximum weight of the load $\mathrm{m}$ is $50 \mathrm{~kg}$. In the weight membership function, the horizontal axis is the input value in the form of mass in $\mathrm{kg}$. While the vertical axis are the membership level of the input value. From the wind speed membership function and weight membership function in Figure 3 and 4, a rule base can be formed as a logic for completion and decision making that will be applied on the PLC leader diagram in determining motor speed.

The rule base table is represented in Table 1. From this table, a decision can be made to determine the speed setting for the moving cable car cable carrier. In this table, there are 9 (nine) conditions with three solutions. The solutions contained in the rule base table include slow, normal and fast. The application of fuzzy logic to the PLC is carried out using the CX Programmer software which is then displayed in the CX Designer.

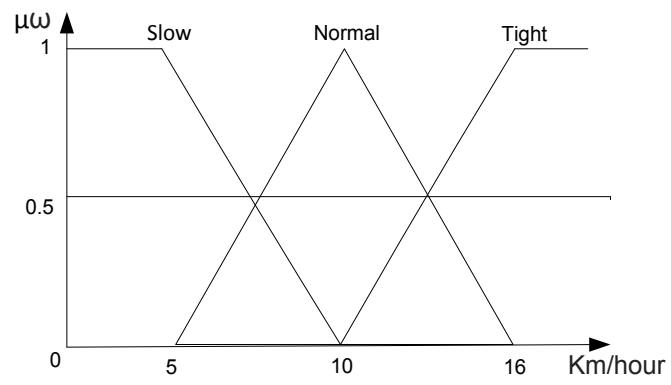

Fig. 3. The wind speed membership function

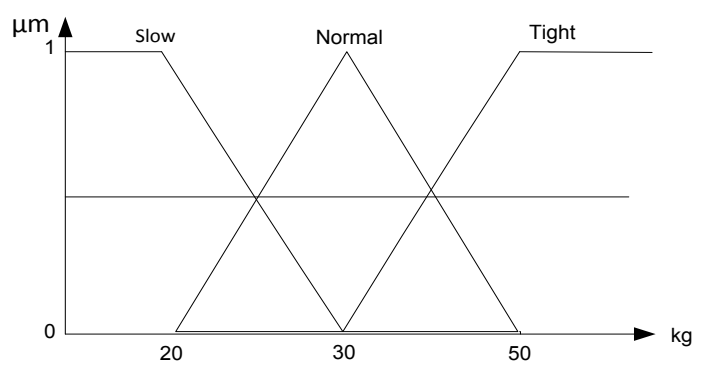

Fig. 4. The weight membership function

TABLE I. RULE BASE FUZZY LOGIC

\begin{tabular}{cccl} 
Wind & & & \\
Weight & Slow & Normal & Tight \\
\hline Tight & Fast & Normal & Slow \\
Normal & Normal & Normal & Slow \\
Weight & Slow & Slow & Slow \\
\hline \hline
\end{tabular}

\section{RESULTS}

Testing in this study was carried out in several stages. The initial stage is a test program made through the HMI display. Starting by activating the power source indicator on the leader diagram from $\mathrm{OFF}$ to $\mathrm{ON}$. The next step is to fill in the parameters on the "Setting Parameters" button on the HMI simulation display in the form of cable car load $(\mathrm{kg})$, wind speed $(\mathrm{km} \mathrm{/} \mathrm{h),} \mathrm{cable} \mathrm{car} \mathrm{speed} \mathrm{(rpm)} \mathrm{and} \mathrm{cable} \mathrm{car} \mathrm{distance.}$ The input in the form of cable car load consists of the maximum allowable load for the cable car to operate and the weight range under normal conditions.

The second parameter is the wind speed $(\mathrm{km} / \mathrm{h})$ which consists of the maximum parameter for the maximum wind speed allowed for the cable car to operate, Normal Range is filled in to get the normal cable car speed value in wind conditions according to the values entered in the two normal parameters. The third parameter is the speed of the cable car (rpm) consisting of the maximum cable car speed which is adjusted to the design, the speed value of the cable car can be classified as fast, normal and slow. Cable car can go fast if one or both of the load and wind speed parameters are below normal parameters. The cable car speed value is classified as normal speed if the load parameters and wind speed are under normal conditions.

The cable car speed value is slow when one or both of the load and wind speed parameters are above normal values. And the last parameter entered is the cable car distance (meter) which consists of the minimum parameter, namely the minimum distance the cable car starts to lower its speed. The maximum distance between cable car stations. When the distance sensor reads above the min value, the cable car speed will depend on the load conditions and wind speed. If it is below the min value, the speed of the cable car depends on the distance of the cable car, the closer it is, the slower the speed is until it stops. The display of the parameter setting design is represented in Figure 6. When all parameters are filled in, the new system can be activated, if you want to simulate, select the simulated button and activate the simulation system by pressing the ON button on the simulation tab screen.

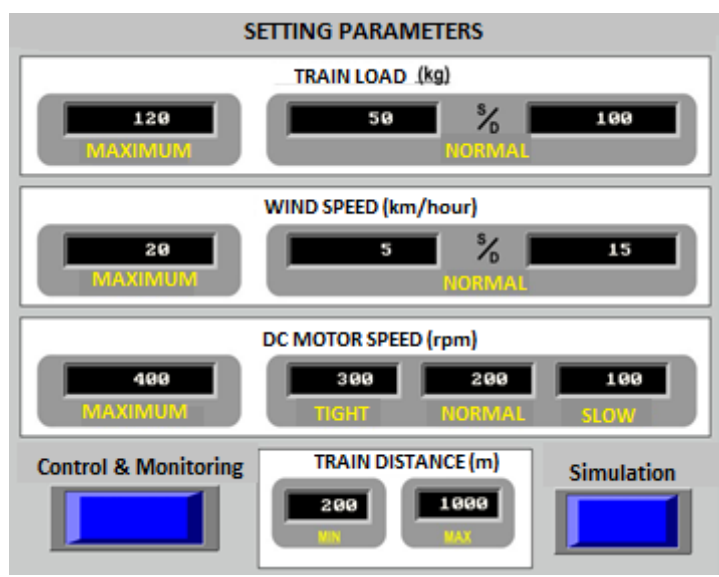

Fig. 5. Setting Parameter 


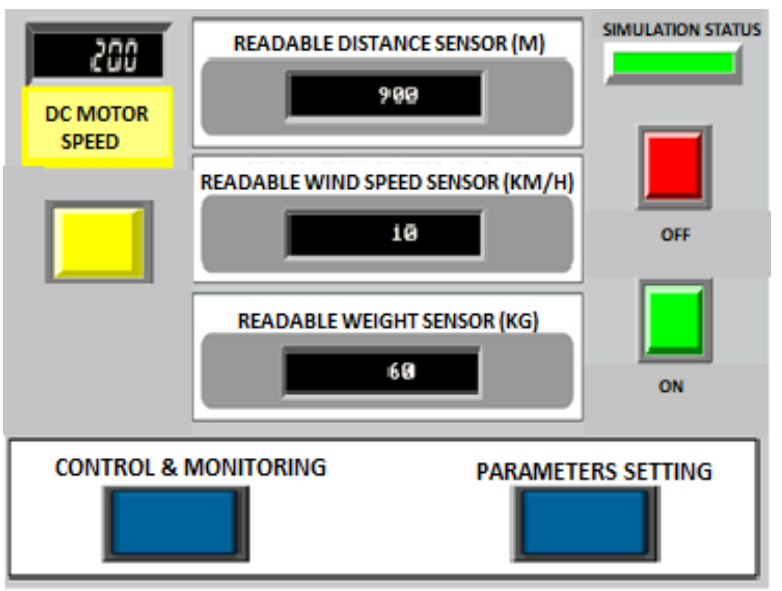

Fig. 6. Sensor Simulation

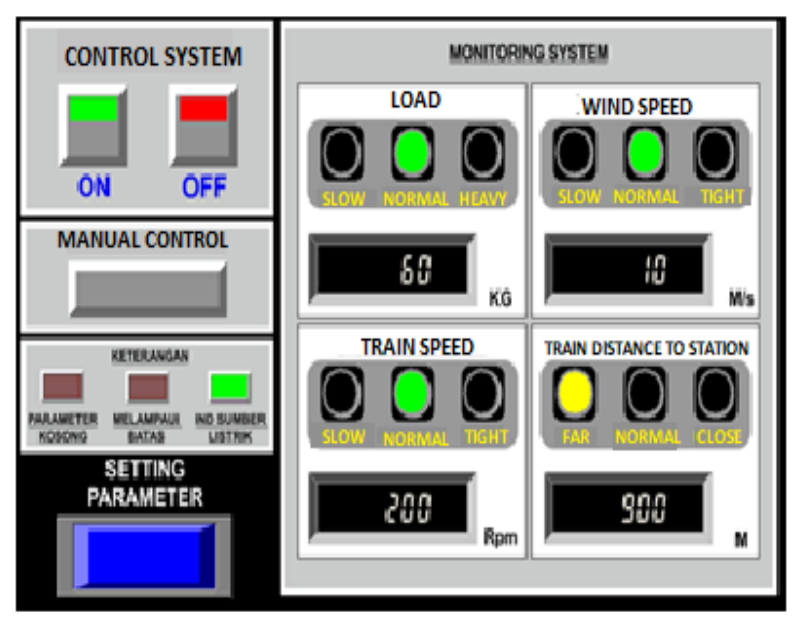

Fig. 7. Monitoring System

\section{DISCUSSION}

In this study, a simulation to minimize the oscillation of cable car vehicles is carried out by controlling the performance of the motor which functions to rotate the cable car carrier using the fuzzy logic method as a data processor which will be used as input to the PLC. The test was carried out with three case studies, namely the cable car test simulation with weight variables, changes in wind speed, and the effect of distance. This is different from [3] research, where minimizing the speed of the cable car is done based on a theoretical model and a single-vehicle system (FUNIFOR).

In this research, there are three case studies i.e. cable car test simulation with weight variable, changes in wind speed, and the effect of distance. The results of cable car test with weight variable are shown in Table 2 . The speed of the cable car is influenced by distance, wind speed and weight. This test is divided into 3 parts. First change in weight first. The heavier the load on the cable car, the slower the cable car speed. If the load weight exceeds the limit, the cable car will automatically turn off.
TABLE II. CABLE CAR SYSTEM TEST DATA WITH WEIGHT VARIABLE

\begin{tabular}{ccccc}
\hline \hline $\begin{array}{c}\text { Distance } \\
(\mathrm{m})\end{array}$ & $\begin{array}{c}\text { Weight } \\
(\mathrm{kg})\end{array}$ & $\begin{array}{c}\text { Wind } \\
\text { Speed } \\
(\mathrm{km} / \mathrm{h})\end{array}$ & $\begin{array}{c}\text { Cable Car } \\
\text { Speed } \\
(\mathrm{Rpm})\end{array}$ & Information \\
\hline 900 & 40 & 10 & 200 & Normal \\
900 & 60 & 10 & 200 & Normal \\
900 & 110 & 10 & 100 & $\begin{array}{c}\text { Slow } \\
\text { OFF } \\
\text { (exceeds } \\
\text { the limit) }\end{array}$ \\
\hline \hline
\end{tabular}

TABLE III. CABLE CAR SYSTEM TEST DATA WITH WIND SPEED VARIABLE

\begin{tabular}{ccccc}
\hline \hline $\begin{array}{c}\text { Distance } \\
(\mathrm{m})\end{array}$ & $\begin{array}{c}\text { Weight } \\
(\mathrm{kg})\end{array}$ & $\begin{array}{c}\text { Wind } \\
\text { Speed } \\
(\mathrm{km} / \mathrm{h})\end{array}$ & $\begin{array}{c}\text { Cable Car } \\
\text { Speed } \\
(\mathrm{Rpm})\end{array}$ & Information \\
\hline 900 & 60 & 10 & 100 & Normal \\
900 & 60 & 18 & 100 & $\begin{array}{c}\text { Slow } \\
900\end{array}$ \\
60 & 3 & 300 & $\begin{array}{c}\text { Fast } \\
\text { OFF } \\
\text { (exceeds } \\
\text { the limit) }\end{array}$ \\
\hline \hline
\end{tabular}

TABLE IV. CABLE CAR SYSTEM TEST DATA WITH DISTANCE VARIABLE

\begin{tabular}{ccccc}
\hline \hline $\begin{array}{c}\text { Distance } \\
(\mathrm{m})\end{array}$ & $\begin{array}{c}\text { Weight } \\
(\mathrm{kg})\end{array}$ & $\begin{array}{c}\text { Wind } \\
\text { Speed } \\
(\mathrm{km} / \mathrm{h})\end{array}$ & $\begin{array}{c}\text { Cable Car } \\
\text { Speed } \\
(\mathrm{Rpm})\end{array}$ & Information \\
\hline 900 & 60 & 10 & 200 & Normal \\
200 & 60 & 10 & 200 & Normal \\
100 & 60 & 10 & 100 & Slow \\
50 & 60 & 10 & 80 & Slow \\
\hline \hline
\end{tabular}

The second test is the effect of changes in wind speed. The effect of this wind speed is very important to the speed of the cable car. The faster the wind speed around the cable car, the faster the cable car speed will be. Therefore, we need wind speed data at the location of the cable car operation area. If the wind speed exceeds the limit, the cable car will also automatically turn off. The cable car test results with wind speed variable are shown in Table 3.

The third test is testing the effect of distance on the operation of the cable car. If the distance is close to the minimum distance, the cable car speed will automatically slow down. So this research combines the influence of wind speed, weight and distance to regulate the speed of the cable car. No one has yet researched various variables. Usually only 1 variable affects the speed setting of the cable car. The cable car test results with distance variable are shown in Table 4. 
The main objective of this research is to know the speed of the cable car with the variable changes in the value of weight, wind speed and distance. Changes in weight, wind speed and distance values can affect the cable car speed values. So that if the cable car system is to be applied to real conditions, the cable car system is ready and can operate properly. The limitation of this study is that only three variables affect the cable car speed value. There is also no security system for weather problems such as rain or lightning.

\section{Conclusion}

The purpose of this research is to control the motor speed based on the industrial era 4.0. Cable car speed is affected by wind speed, weight, and distance. Cable cars can run fast or slow depending on the wind, weight and distance. The safety of the cable car system is further developed under the influence of weather conditions. On the next opportunities, a cable car prototype design will be carried out with these controls before being implemented in the real system and determination of parameter values that is done manually can be done automatically using sensors. So that the parameters can be changed in real time.

\section{REFERENCES}

[1] W. Pribadi and Y. Prasetyo, "Sistem Kontrol Motor Dc Brushless Dengan Fix Frequency Hybrid Fuzzy Logic Controller," J. Electr. Electron. Control Automot. Eng., vol. 4, no. 2, pp. 269-272, 2019.

[2] W. Lu and X. Wei, "Spatio-temporal Distribution Pattern of Cable Car Passenger Flow in Panholidays: A Case Study of Huangshan Scenic Area," Proc. - 2017 IEEE 2nd Int. Conf. Data Sci. Cyberspace, DSC 2017, pp. 35-42, 2017, doi: 10.1109/DSC.2017.75.

[3] M. Wenin, A. Windisch, S. Ladurner, M. L. Bertotti, and G. Modanese, "Optimal velocity profile for a cable car passing over a support," Eur. J. Mech. A/Solids, vol. 73, no. August 2018, pp. 366-372, 2019, doi: 10.1016/j.euromechsol.2018.09.013.

[4] H. Maghfiroh, "in Speed Control f DC Motor Base on PLC," Int. Conf. Instrum. Control Autom., no. Figure 1, pp. 233-238, 2013.

[5] Y. Prasetyo, B. Triyono, and A. Choirul Arifin, "Optimalisasi Daya Output Dual Axis Solar Tracker Dengan Metode Umbrella System," $J$. Geuthëë Penelit. Multidisiplin, vol. 02, no. 02, pp. 267-274, 2019.

[6] W. Pribadi, Y. Prasetyo, and D. E. Juliando, "Design of Fish Feeder Robot based on Arduino- Android with Fuzzy Logic Controller," Int. Res. J. Adv. Eng. Sci., vol. 5, no. 4, pp. 47-50, 2020.

[7] J. Kocian, J. Koziorek, and M. Pokorny, "An approach to PLC-based fuzzy control," Proc. 6th IEEE Int. Conf. Intell. Data Acquis. Adv. Comput. Syst. Technol. Appl. IDAACS'2011, vol. 1, no. September, pp. 322-327, 2011, doi: 10.1109/IDAACS.2011.6072766. 